\title{
THE FACTORS AFFECTING THE SEA TRANSPORTATION IN THE NEW GLOBALIZATION ERA
}

\author{
DOI: 10.17261/Pressacademia.2018.960 \\ JMML- V.5-ISS.3-2018(1)-p.166-171
}

\section{Soner Esmer}

Dokuz Eylul University, Maritime Faculty, Izmir, Turkey. soner.esmer@gmail.com, ORCID: 0000-0002-0614-7818

To cite this document

Esmer, S. (2018). The factors affecting the sea transportation in the new globalization era. Journal of Management, Marketing and Logistics (JMML), V.5(3), p.166-171.

Permemant link to this document: http://doi.org/10.17261/Pressacademia.2018.960

Copyright: Published by PressAcademia and limited licenced re-use rights only.

\begin{abstract}
Purpose- to identify the variables that define the new globalization model from the point of view of the container shipping and port industry and to rank these variables by their importance.

Methodology- A research process involving both qualitative (semi-structured interview) and quantitative method (Fuzzy AHP) has used to collect and analyse data.

Findings- According to the findings, there are 9 basic variables that will affect maritime transport and the port in the future.

Conclusion- the most influential variables of the new globalization model that will affect the maritime transport in the future will be cybersecurity threat, Industry 4.0 technologies and climate change.
\end{abstract}

Keywords : Sea transport, globalization, cybersecurity, industry 4.0, climate change.

JEL Classification: F60, L91, R41

\section{INTRODUCTION}

In the world, the manufacturing industry has slowed down in response to the global financial crisis in 2008, especially after 2012, global commodity trade has almost fallen to GDP growth rates. In 2016, for the first time since 2001, commodity trading has remained below the world GDP growth rate of 1.3\%. Between 2001 and 2008 container transport increased by an average of $10.8 \%$ per year, while growth between 2011 and 2016 was only 3.9\% (Saxon \& Stone, 2017). These statistics are far from the usual statistics in the 1990s and in the first half of the 2000s. It is understood that from these data, the world classical globalization model is changing.

It is inevitable that the logistics and maritime transport sector like every sector will be influenced by this change. While maritime transport being always in an important part in global logistics activities, it is not clear which variables will affect the maritime transportation in the future. This uncertainty constitutes the basic motivation for the research.

In this study, the basic variables of the new globalization model and the effects of these variables on the maritime transportation are questioned. The literature has revealed fundamental variables, followed by interviews with experts from the maritime industry and variables that will affect the maritime industry in the future. With the Fuzzy AHP study conducted with the same experts, the rank and importance of the variables have been determined.

\section{LITERATURE REVIEW}

Globalization has a very fundamental link with transport and logistics (Tavasszy et al, 2003). From a mega container ship to a small truck, the entire distribution system is integrated with production activities in global markets. Thus, globalization is supported and spread by the development of modern transport systems (Rodrigue, 2016). However, the role of transport in 
the global economy since the beginning of the 21st Century is in a significant change. The motivators of this change in the global transport system can be classically grouped into six main groups: politics, society and demography, environment and energy, economics, finance and technology (Rodrigue, 2010). These variables play important roles together and separately. The process referred to as the "New Globalization Model" after the 2008 global financial crisis differs with the fact that it is more knowledge-based rather than labour or capital intensive (Tyson \& Lund, 2017).

The main reasons of the new globalization model are the slowing down of economic growth in developing countries including China (1), the tendency to decrease in demand for products as a result of the increase in average age ratios in developed countries and the importance of the service sector (2), the productivity gains achieved in production technologies, (3) and increasing countries' protectionism policies in response to the classic model of globalization (Saxon \& Stone, 2017, Bhattacharya et al, 2017).

It is expected that this change will cause significant changes in global commerce and maritime transport that is used $90 \%$ in the global supply chain. The International Transport Forum (ITF), for example, emphasized that economic geography in developing countries will be affected by changes in consumption and local demand, and the new economic model will be pioneering in the coming period where the low-cost labour-based production model will no longer apply. According to the ITF, the quantities of goods carried in the world between the years 2015 and 2030 will increase by $4.2 \%$ per annum, and after 2030 it will fall to $3.3 \%$. While the flow rate of goods in developed countries is low, the flow of goods among the developing countries themselves will be high (OECD/ITF, 2017).

So which elements of this new globalization model will most impact the maritime industry? There is no clear answer to this question yet. Aggelakakis et al. (2015) prepared a report for the EU Commission entitled "Future of the Transport Industry" which is set out the variables that will affect the transport industry. These variables are predominantly derived from the Bernardino et al. (2013) study. The variables include climate change, globalization, urbanization, ageing, increasing knowledge of the community, individuality, migrations, connectivity, urgent needs (here\&now), slow movement, women's strengthening in society, awareness, consciousness, the trends of being young, seeking for experience and do it yourself. Bernardino et al. (2013) called these variables "key drivers of transport demand evolution".

\section{DATA AND METHODOLOGY}

In this study, it is aimed to determine the key future factors affecting maritime transport. A research process involving both qualitative and quantitative methods has used to collect and analyse data (Eisenhardt, 1989, Johnson \& Onwuegbuzie, 2004). A semi-structured interview technique is an ideal method for in-depth understanding of the topic in qualitative research (Wilson, 2011). In this study, semi-structured interview form has applied to experts for finding basic variables, then the variables have ranked by Fuzzy Analytic Hierarchy Process (Fuzzy AHP).

\subsection{Sampling}

Boddy (2016) stated that 12 interviews are sufficient to reach the theoretical satisfaction in a qualitative research. On the other hand, when theoretically new variables are not produced, the sample size is assumed to be at a satisfactory level (Bryman, 2008).

According to Rodrigue (2010) "Maritime transport is composed of the maritime shipping and the ports dimensions". 12 of the 24 interviews conducted in this study were carried out by experts from the maritime shipping sector and the remaining 12 were conducted by experts in the port sector. While 12 of these experts living in Turkey, the rest 4 in Dubai, another 4 in Singapore, 3 in China and 1 is living in Hamburg. Half of the interviewees work in global container line operators and the others work in global container terminal operators as a senior manager. The main reason for selection of an equal number of administrators by shipping line and port is a balanced determination of the distinction between both sides. Interviewees have selected by judgemental sampling method so that the choice of the people who could answer the questions has secured (Malhotra, 2008)

\subsection{Qualitative Research Process: Semi-structured Interview}

The experts were asked about the variables related to the new globalization model that is expected to affect maritime transport in the future. Twelve interviews were conducted face-to-face, while the remaining twelve were conducted by video call. Interviews lasted approximately 50 minutes and records were kept. As a result of the interviews, 9 variables were determined.

\subsection{Quantitative Research Process: Fuzzy AHP}

In this study, the Fuzzy AHP method has applied to find the weights of the 9 variables obtained from the interviews. Saaty has used the expression "the method of determining priority orders with pairwise comparisons of judges obtained from 
experts" when defining the AHP method (Saaty, 2008). Although the method was developed by Saaty in 1977, it has been widely used in many academic disciplines (Vaidya \& Kumar, 2006).

There are 3 basic levels in a typical AHP structure. At the top level, the objectives of the research are shown, while the second level is the criteria. Although there are alternatives to choose from at the bottom, there is no third level in this work due to the purpose of the study.

The questionnaire prepared for this research has two sections. The first part consists of the profile questions about the participants and the second part contains the pairwise comparison of the variables obtained from the interviews before.

In the questionnaires, a 9-point comparative scale has used as suggested by Saaty (2008). The questionnaires have replied by 24 experts who conducted the interviews in January and February 2018.

Then the Fuzzy AHP method has applied. The reason for not applying the classical AHP method at this point is that it is criticized because it is inadequate to handle the uncertainty and indecision situations (Deng, 1999). The focal point of these criticisms is that the acceptance of "something right or wrong" in classical logic does not overlap much with real life, and does not reflect the way human thinking works. In real life, however, there could be many situations between right and wrong.

The article entitled "Fuzzy Sets" published by Zadeh (1965) has been adapted to the AHP method as well as many other scientific methods. The Fuzzy AHP method, which is able to make more consistent decisions because it is very close to the logic of human thinking, has a more advanced technique than Saaty's classic AHP (Yu, 2002, Sheu, 2004).

Fuzzy numbers do not form a natural order like real numbers. For this reason, there are many studies in the literature for ranking the fuzzy numbers (Jain, 1976, Bortolan \&Degani, 1985, Bass \& Kwakernaak, 1977, Chen \& Hwang, 1992, AbdelKader \& Dugdale, 2001, Ezati et al., 2012, Liou, 1992, Kwong \& Bai, 2003). In addition to these studies, Chang (1996) developed a new approach and used triangular fuzzy numbers for pairwise comparison scales in the Fuzzy AHP. In this study, the widely used Fuzzy AHP method proposed by Chang (1996) has been used. The choice of this method is due to the low computational requirement and the use of classic AHP steps.

\section{FINDINGS AND DISCUSSIONS}

\subsection{Interview Results}

According to the results obtained from the interviews, there are 9 basic variables that will affect maritime transport and the port in the future. These variables and the basic opinions expressed by interviewees regarding these variables are as follows:

C1- Industry 4.0 technologies: Industry 4.0 is the industry's digital transformation. Intelligent robots that can respond quickly to customer requests with flexibility and productivity in production refer to 8 basic technologies such as the Internet of Things (IOT) and big data analysis. It is thought that these technologies will deeply affect not only the production but also the service sector. For example, with loT, the transparency, efficiency and reliability of the supply chain and environmental awareness will increase with efficient resource planning. 3D printers will reduce transport demands, and transport will be predominantly directed at raw material shipments. With autonomous devices, the demand for labour force will be reduced and the performance of delivery processes will increase. With industrial robots, production efficiency will increase, production cost and dependence on labour force will decrease.

C2- Digital vulnerability and cybersecurity threat: With the impact of mobile devices, digitalization has begun in every area of the world, and digital markets have become the most important markets. Technically it is not possible to switch to Industry 4.0 technology without digitalization. However, digitalization is bringing about security issues. Increasing dependence on digital markets requires measures against risks. Cyber-attacks for digital data and data breach violations have become a major threat. With cyber-attacks, IT systems are collapsing, which can lead to significant loss and disruption in business processes. As a matter of fact, it is stated that Maersk suffered a loss of 300 million dollars in the third quarter due to the cyber-attack in 2017 (Wienberg, 2017). While it is difficult to keep up with this fast digital change process and technological progress, it is very much reliant on these technologies. Much more sophisticated models of operation emerge in the business world where interconnectivity is constantly increasing.

C3- Political imbalances and protectionism policies: It is estimated that in 2015 , there will be an additional cost of $\$ 56$ billion in the global supply chain due to unexpected weather changes, terrorism, forced migrations and criminal activities in the world (BSI, 2016). In addition, the increasing complexity of regulations, the excessive and unpredictable political decisions of governments, the increase in safety and security rules, slowdown of operations due to safety concerns, protectionism policies that restrict competition, foreign trade customs procedures and taxes, changes in macro environmental factors, it will continue to create constraints in future commercial activities and in the transport sector. 
C4- Disruptive innovation: Many destructive innovations are expected in the future (Hyperloop, unmanned ships, drones, etc.) and new technologies are a threat to existing transportation vehicles and infrastructures.

C5- Climate change: Increasing precipitation affects the smooth operation of radar and radio equipment on ships, causing drainage systems in ports to be inadequate and storage areas to be damaged. Increased average temperatures cause damage to railways and roads, increasing the energy consumption of refrigerated containers. Storms cause the container to overturn in the port, increase the wave power and coastal erosion. On the other hand, storms cause the wave breakers and breakers in the ports to be inadequate. Rapid escalating winds adversely affect navigation and communication equipment, delay vessel port operations, damage old buildings and warehouse.

C6- Return of production (Localization): With the reduced dependence on labour, it is expected that the return of production to the nearest point in developed countries will have a shortening effect on the global supply chain.

C7- Change in business model: Factors such as changes in customer needs and expectations, threats created by emerging and emerging competitors, and increased costs of risk reduction put pressure on managers to create a much more dynamic business model. This new business model has to be resilient to the growing fragility of global markets. It is thought that these business models will also affect the business models of maritime transport.

C8- Urbanization: With controlled and uncontrolled migration, the population is concentrated in large cities. This is another important reason for the production facilities to be deployed around these cities. Especially urban logistics is expected to gain much more importance.

C9- Ageing: Especially in the developed countries, the increase in the average age causes the service sector to gain importance and increase the usage habit (Consumption 2.0) instead of buying the products, which is considered as an element that can negatively affect the global commodity trade.

\subsection{The Results of Fuzzy AHP}

In order to be able to determine the significance ratings of the criteria, the same decision makers have asked to answer the 9-point scale questionnaires based on pairwise comparisons. Then the data has transformed into a triangular fuzzy number by reducing the evaluations of these 24 decision makers to a single value to indicate the outcome of each decision maker's criterion (Table 1).

Table 1: Fuzzy Comparison Matrix

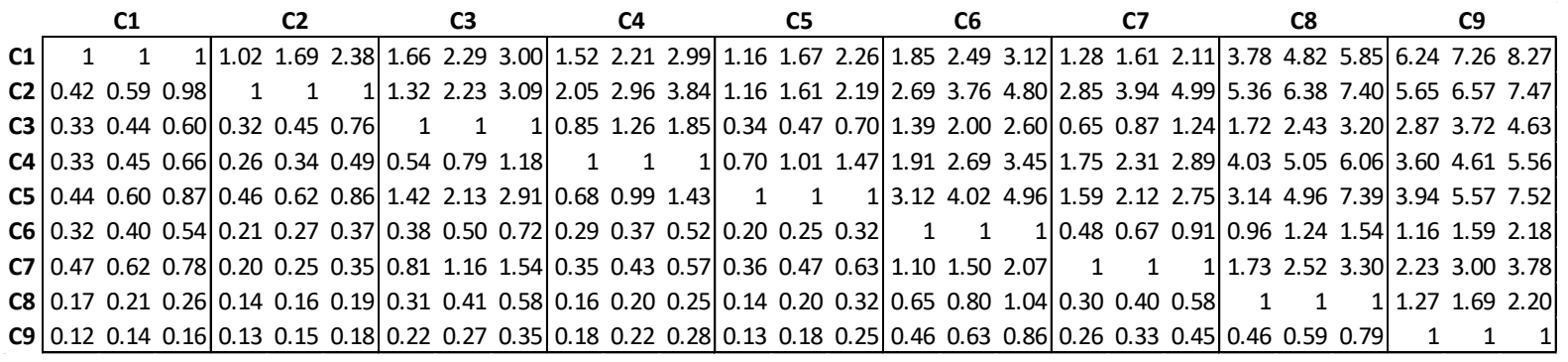

Finally, the weights of each criterion have calculated by the Fuzzy AHP method (Table 2).

Table 2: The Overall Importance of All Responses

\begin{tabular}{|ll|}
\hline Criteria & Weight (\%) \\
\hline C2- Digital vulnerability and cybersecurity threat & 24,1 \\
C1- Industry 4.0 technologies & 22,3 \\
C5- Climate change & 17,5 \\
C4- Disruptive innovation & 13,4 \\
C3- Political imbalances and protectionism policies & 10,6 \\
C7- Change in business model & 8,8 \\
C6- Return of production (Localization) & 5,6 \\
C8- Urbanisation & 4,0 \\
C9- Ageing & 3,0 \\
\hline Number of respondents & 24 \\
\hline
\end{tabular}


Given the general conclusions of the 24 decision makers, it has been determined that the three most important variables that are expected to affect the maritime industry in the future are the cybersecurity threat, Industry 4.0 technologies and climate changes. These three variables are followed by disruptive innovations, political imbalances and protectionism.

On the other hand, the importance ranks of the two groups have calculated to see the disagreement of the participant groups is shown in Table 3.

Table 3: Respondent Groups' Comparisons

\begin{tabular}{|lllll|}
\hline & \multicolumn{2}{l}{$\begin{array}{l}\text { Ship } \\
\text { Operators }\end{array}$} & \multicolumn{2}{l|}{$\begin{array}{l}\text { Operminal } \\
\text { Operators }\end{array}$} \\
\cline { 2 - 5 } Criteria & $\begin{array}{l}\text { Weight } \\
\text { (\%) }\end{array}$ & Rank & $\begin{array}{l}\text { Weight } \\
(\%)\end{array}$ & Rank \\
\hline C1- Industry 4.0 technologies & $28,0 \%$ & 1 & $17,4 \%$ & 3 \\
C2- Digital vulnerability and cyber security threat & $23,9 \%$ & 2 & $23,9 \%$ & 1 \\
C5- Climate change & $15,2 \%$ & 3 & $19,9 \%$ & 2 \\
C4- Disruptive innovation & $12,8 \%$ & 4 & $13,8 \%$ & 4 \\
C3- Political imbalances and protectionism policies & $10,0 \%$ & 5 & $11,1 \%$ & 5 \\
C7- Change in business model & $7,4 \%$ & 6 & $10,3 \%$ & 6 \\
C6- Return of production (Localization) & $5,5 \%$ & 7 & $5,7 \%$ & 7 \\
C8- Urbanisation & $4,0 \%$ & 8 & $3,9 \%$ & 8 \\
C9- Ageing & $2,4 \%$ & 9 & $3,8 \%$ & 9 \\
\hline Number of respondents & 12 & & 12 & \\
\hline
\end{tabular}

Although the order of the first three variables is different in the two groups, the order of the other variables have remained the same. While ship operators think that the maritime industry will be the most influential variable in the future for Industry 4.0 technologies, port operators think that the most important variables are "digital vulnerability" and "cybersecurity threats".

\section{CONCLUSION}

The logistics sector is directly affected by economic activity around the world. In recent years, fundamental changes in the basic statistics on world economy and trade have revealed some doubts about the future of the logistics industry. It is difficult to determine how much the economic, technological, social, demographic and legal factors that are often mentioned today will affect the logistics industry in the future. However, it is relatively possible to identify these variables and to find their significance. In this study, interviews with experts in the maritime industry revealed potential variables that will affect the maritime industry in the future. These variables have then ranked according to their significance from the point of view of both port and shipping sector representatives.

Taking into account all the responses of both ship and port operators, it is clear that the threat of cybersecurity is considered to be the most likely future element in the maritime industry. The second important variable, Industry 4.0 , is in fact directly related to the first variable. Because Industry 4.0 is at the heart of digitalization and the digitalization of all business processes brings together digital vulnerability and cybersecurity threats. These two variables also at the top rank, when the responses of the ship operators are taken into consideration. When the only responses of port operators are taken into consideration, it is seen that the first two rows are accompanied by the cybersecurity threat and the climate change. Considering the possible negative effects of the climate change on the ports, this can be regarded as expected.

The most important limitation of the study is that it is applied only to the container transport sector and the other transport modes may be taken into account in further studies.

\section{REFERENCES}

Abdel-Kader, M., Dugdale, D. (2001). Evaluating investments in advanced manufacturing technology: a fuzzy set theory approach. British Accounting Review, 33, 455-489.

Aggelakakis, J., Bernandino, M., Boile, P., Christidis, A., Condeco, M., Krail, A., Papanikolaou, M., Reichenbach. J. (2015). The future of the transport industry. European Commission Joint Research Centre Institute for Prospective Technological Studies.

Baas, S. M., Kwakernaak, H. (1977). Rating and ranking of multiple aspect alternatives using fuzzy sets. Automatica, $13,47-58$.

Bernardino, J., Vieira, J., Garcia, H. (2013). Factors of evolution of demand and methodological approach to identify pathways. FUTURE Deliverable D3.1. Project financed by the 7th Framework Programme. 
Bhattacharya, A., Khanna, D., Schweizer, C., Bijapurkar, A. (2017). The new globalization: going beyond the rhetoric. Boston Consulting. Boddy, C. R. (2016). Sample size for qualitative research. Qualitative Market Research: An International Journal, 19(4), 426-432.

Bortolan, G., Degani, R. (1985). A review of some methods for ranking fuzzy numbers. Fuzzy Sets and Systems, 15, 1-19.

Bryman, A. (2008). Social research methods. Oxford university press, $4^{\text {th }}$ edition.

BSI. (2016) the British Standards Institution report. https://www.bsigroup.com/Documents/about-bsi/financial-performance/2016/BSIAnnual-report-and-financial-statements-2016.pdf

Chang, D. Y. (1996). Applications of the extent analysis method on fuzzy AHP. European Journal of Operational Research, 95(3), 649-655.

Chen, S. J., Hwang, C. L. (1992). Fuzzy multiple attribute decision making methods. In: Fuzzy Multiple Attribute Decision Making. Lecture Notes in Economics and Mathematical Systems, 375. Springer, Berlin, Heidelberg.

Eisenhardt, K. M. (1989). Building theories from case study research. Academy of management review, 14(4), 532-550.

Ezzati, R., Allahviranloo, T., Khezerloo, S., Khezerloo, M. (2012). An approach for ranking of fuzzy numbers. Expert Systems with Applications, 39, 690-695.

H. Deng, (1999). Multicriteria analysis with fuzzy pairwise comparison. International Journal of Approximate Reasoning, 21, 215-231.

Jain, R. (1976). Decision making in the presence of fuzzy variable. IEEE Trans Systems Man and Cybernet SMC, 6, pp. 698-703.

Johnson, R. B., Onwuegbuzie, A. J. (2004). Mixed methods research: a research paradigm whose time has come. Educational Researcher, $33(7), 14-26$.

Kwong, C. K., Bai, H. (2003). Determining the importance weights for the customer requirements in QFD using a fuzzy AHP with an extent analysis approach. IEE Transactions, 35(7), 619-626.

Liou, T. S., Wang, M. J. (1992). Ranking fuzzy numbers with integral value. Fuzzy Sets and Systems, 50(3), 247-255.

Malhotra, N. K. (2008). Marketing research: an applied orientation, 5/e, Pearson Education India.

OECD/ITF (2017). ITF transport outlook 2017, OECD Publishing, Paris. http://dx.doi.org/10.1787/9789282108000-en

Rodrigue, J. P. (2006). Transportation and globalization. Encyclopaedia of Globalization, Edited by Roland Robertson and Jan Aart Scholte. Routledge.

Rodrigue, J. P. (2010). Maritime transportation: drivers for the shipping and port industries. International Transport Forum, Paris.

Saaty, T. L. (2008). Decision making with the analytic hierarchy process. International journal of services sciences, 1(1), 83-98.

Saaty, T. L. (1977). A scaling method for priorities in hierarchical structures. Journal of mathematical psychology, 15(3), 234-281.

Saxon, S., Stone, S. (2017). Container shipping, the next 50 years. McKinsey\&Company. Travel, Transport \& Logistics.

Sheu, J. B. (2004). A hybrid fuzzy-based approach for identifying global logistics strategies. Transportation Research, 40(1), 39-61.

Tavasszy, L. A., Ruijgrok, C. J., Thissen, M. J. P. M. (2003). Emerging global logistics networks: implications for transport systems and policies. Growth and Change 34(4), 456-472.

Tyson, L. D., Lund, S. (2017). Globalization isn't in retreat. It's just gone digital. https://www.weforum.org/agenda/2017/02/whyglobalization-isnt-it-in-retreat-its-gone-digital

Vaidya, O. S., Kumar, S. (2006). Analytic hierarchy process: an overview of applications. European Journal of operational research, 169(1), $1-29$.

Wienberg, C. (2017). Maersk says June cyberattack will cost it up to $\$ 300$ million. https://www.bloomberg.com/news/articles/2017-0816/maersk-misses-estimates-as-cyberattack-set-to-hurt-third-quarter

Wilson, A. (2011) Marketing research: an integrated approach. FT Prentice Hall.

Yu, C. S. (2002). A GP-AHP method for solving group decision-making fuzzy AHP problems. Computers \& Operations Research, 29(14), 19692001.

Zadeh, L. A. (1965). Fuzzy sets. Information and Control, 8, 338- 353. 